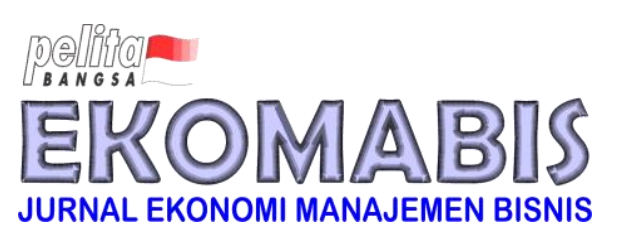

\title{
Mendorong Loyalitas Melalui Kualitas Pelayanan dan Kepercayaan
}

\author{
Encouraging Loyalty Through Quality Service and Trust
}

Submit: 05 Jan 2021 Review: 12 Jan 2021 Accepted: 27 Jan 2021 Publish: 02 Feb 2021

Irwan Kurniawan ${ }^{1}$; Rr Titin Maidarti ${ }^{2}$; Ris Handayani ${ }^{3}$

\begin{abstract}
ABSTRAK
Penelitian untuk mengetahui pengaruh kualitas layanan sebagai variabel independen pertama dan kepercayaan sebagai variabel independen kedua terhadap loyalitas pelanggan produk UMKM sebagai variabel dependen. Metode Survey melibatkan responden melalui teknik pengambilan sampel yang purposive non random sampling sejumlah 40 konsumen yang pernah menggunakan layanan pembelian UMKM Kuliner di wilayah Cileungsi secara online. Data primer diperoleh dengan menyebarkan kuesioner. Beberapa uji diterapkan berupa instrumen kuesioner, normalitas, dan regresi berganda. Beberapa temuan dalam penelitian adalah kedua variabel independen yaitu kualitas layanan sebagai independen pertama dan kepercayaan sebagai variabel independen kedua berpegaruh positif terhadap loyalitas sebagai variabel dependen.
\end{abstract}

Kata kunci: Kualitas pelayanan, kepercayaan, loyalitas

\begin{abstract}
Research to determine the effect of service quality as the first independent variable and trust as the second independent variable on customer loyalty of MSME products as the dependent variable. The survey method involved respondents through a purposive non-random sampling technique of 40 consumers who had used online MSME culinary purchasing services in the Cileungsi area. Primary data obtained by distributing questionnaires. Several tests were applied in the form of a questionnaire instrument, normality, and multiple regression. Some of the findings in the study are that the two independent variables, namely service quality as the first independent and trust as the second independent variable, have a positive effect on loyalty as the dependent variable.
\end{abstract}

Keywords: Service quality, trust, MSMEs, customer loyalty

${ }^{1}$ Sekolah Tinggi Ilmu Ekonomi IPWI Jakarta; h_irwan74@yahoo.co.id

2 Sekolah Tinggi Ilmu Ekonomi IPWI Jakarta; titin2meidarti@gmail.com

3 Sekolah Tinggi Ilmu Ekonomi IPWI Jakarta; handayaniris40@gmail.com 


\section{Pendahuluan}

Keberlangsungan bisnis UMKM sepanjang 2020 di masa pandemi Covid 19 banyak yang mengalami kendala, sebagian mampu bertahan dengan menggunakan layanan online. Konsumen dalam memilih produk dipengaruhi oleh banyak hal seperti produk, promosi, harga dan kemudahan memperoleh produk yang dibeli. Interaksi konsumen dengan perusahaan diharapkan meningkatkan pembelian kembali pada perusahaan yang sama yang menguat menjadi konsuen yang loyal. Loyalitas konsumen semakin sulit dicapai ketika di pasar terdapat banyak perusahaan dan ragam alternatif produk yang memudahkan konsumen beralih.

Loyalitas yang dimiliki konsumen akan menguntungkan perusahaan. Konsumen yang loyal akan melakukan pembelian ulang. Perusahaan dapat menghemat biaya untuk menambah pelanggan baru. Loyalitas yang penting menjadi perhatian banyak peneliti (Nurbani, Mulyanto, Wardani dan Andriyani, 2019; Huda dan Nugroho, 2020; Taufik, 2017; Tumbel, 2016; Lapasiang, Moniharapon \& Loindong, 2017).

Banyak ragam yang mempengaruhi loyalitas. Beberapa diantaranya adalah kualitas pelayanan dalam berbagai bentuk (Trisusanti, 2017; Alwi, 2018), kepuasan (Zakiy, 2017; Alwi, 2018), kepercayaan merek dan Kualitas (Trisnawati, Sume \& Muniroh, 2020). Diantara stimulus perusahaan adalah produk (barang dan jasa) yang terkait kualitas layanan di satu sisi dan aspek kepercayaan konsumen dalam mempengaruhi loyalitas pelanggan.

Kualitas layanan dan kepercayaan menjadi begitu penting dalam mendorong loyalitas. Namun beberapa penelitian tidak mengaitkan dua hal tersebut. Bahkan di beberapa penelitian kualitas layanan mempengaruhi kepuasan (Zakiy, 2017; Asti dan Ayuningtyas, 2020; Andriyani dan Ardianto, 2020) dan komitmen (Taufik, 2017). Sedangkan kepercayaan dalam penelitian sebelumnya baru sampai pada minat beli (Mulyanto, Rasipan, dan Andriyani, 2018) dan pembelian ulang (Dwipayana \& Sulistyawati, 2018).

Diantara aspek yang diteliti oleh beberapa peneliti sebelumnya, terdapat sebagian yang meneliti aspek internal dan sebagian lainnya meneliti aspek eksternal yang mempengaruhi loyalitas pelanggan. Sebagian peneliti membahas aspek kepercayaan pelanggan yang merupakan faktor eksternal yang tidak bisa dikontrol (uncontrollable) oleh pengusaha dan sebagian lain meneliti variabel kualitas layanan yang merupakan faktor internal yang bisa dikontrol (controllable) oleh pengusaha dalam mempengaruhi loyalitas pelanggan.

Penelitian ini akan mengkombinasikan secara spesifik kualitas layanan sebagai faktor pertama dan kepercayaan sebagai faktor kedua terhadap loyalitas pelanggan dari konsumen produk UMKM, untuk mengkombinasikan aspek eksternal berupa kepercayaan pelanggan serta aspek internal berupa kualitas layanan dalam mempengaruhi loyalitas pelanggan. 


\section{Metodologi}

\subsection{Pengembangan Model}

\subsubsection{Loyalitas}

Kesediaan konsumen tetap menggunakan produk yang sama merupakan bentuk loyalitas. ketetapan pelanggan bertahan menjadi pelanggan dan melakukan pembelian ulang menurut Oliver (Hurriyati, 2005:128) itulah yang disebut loyalitas. Kesetiaan dapat ditunjukkan keinginan membeli kembali, merekomendasikan dan tidak beralih.

Loyalitas membuat konsumen tidak beralih. Konsumen yang bersedia membeli mengurangi beban biaya promosi. Penghematan yang terjadi tentu saja mengurangi biaya yang dikeluarkan sehingga pendapatan perusahaan meningkat.

\subsubsection{Kualitas Pelayanan dan Loyalitas}

Kemampuan perusahaan melayani konsumen dapat dinilai berdasar kualitasnya. Layanan yang dinilai baik oleh konsumen menunjukkan kualitas yang baik. Konsumen yang dilayani dengan cepat akan bersedia memberikan testimoni yang positif dan menginformasikan kepada orang lain. Konsumen yang keluhannya direspon cepat akan cenderung kembali (Trisusanti, 2017).

Penelitian sebelumnya (Zakiy, 2017) menunjukkan kualitas pelayanan di Bank Syariah mempengaruhi loyalitas pelanggan. Penelitian lain banyak yang temuannya sama (Alwi, 2018) pada kasus pembelian online. Kondisi ini menghasilkan hipotesis:

\section{H1: Kualitas Pelayanan berpengaruh terhadap loyalitas.}

\subsubsection{Kepercayaan dan Loyalitas}

Kesediaan konsumen bersandar pada sesuatu merupakan kepercayaan. Kepercayaan bisa meliputi keseluruhan atau hanya sebagian dari keseluruhan yang ada. Keyakinan bahwa perusahaan akan memenuhi harapan konsumen merupakan rasa percaya. Kepercayaan salah satunya bisa lahir karena reputasi yang dimiliki perusahaan (Mulyanto, Rasipan, Andriyani, 2018).

Konsumen yang percaya janji dari perusahaan properti, minimal akan merekomendasikan atau menginformasikan kepada keluarga atau teman di sekitarnya (Nurbani, Mulyanto, Wardani, Andriyani, 2019). Kepercayaan merek salah satunya akan mempengaruhi loyalitas pelanggan oppo (Huda dan Nugroho, 2020). Kepercayaan yang tinggi berdampak pada pembelian ulang (Dwipayana \& Sulistyawati, 2018). Semakin tinggi kepercayaan akan semakin tinggi pula loyalitas pelanggan (Taufik, 2017; Tumbel, 2016, Lapasiang, Moniharapon, Loindong, 2017). Kondisi ini menghasilkan hipotesis:

H2: Kepercayaan berpengaruh terhadap loyalitas. 


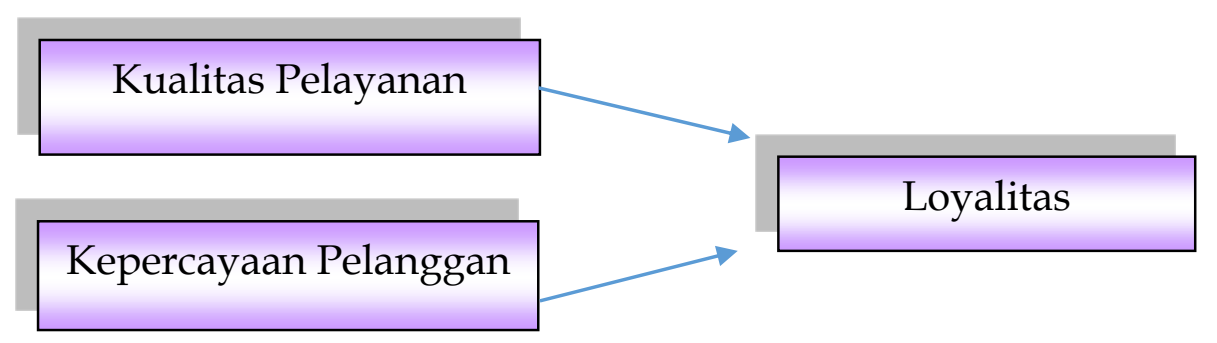

Sumber: rangkuman teori, 2020

\section{Gambar 1. Model Penelitian}

\subsection{Pengambilan Data}

Penelitian ini dialkasanakan Januari sampai April 2020. Populasi penelitian adalah konsumen yang pernah menggunakan layanan pembelian online. Pengambilan sampel dengan purposive sampling (Mulyanto dan Wulandari, A, 2010) sejumlah 40 konsumen yang pernah menggunakan layanan pembelian online. Data primer diperoleh dengan menyebarkan kuesioner pada sampel tersebut sebagai responden.

\subsection{Metode Analisis}

Data hasil kuesioner diuji validitas dan reliabilitasnya terlebih dahulu. Pengujian dengan korelasi product moment untuk uji validitas. Kriteria valid jika diperoleh korelasi hitung lebih besar dari 0,3. Cronbach's alpha digunakan untuk uji reliabilitas dimana reliabel dicapai jika CA nya lebih besar dari 0,6 (Mulyanto dan Wulandari, A, 2010).

Data hasil kuesioner dibuat rata-rata untuk tiap variabel dan dipastikan normalitasnya. Chi square digunkan untuk uji normalitas. Data dipastikan telah normal jika nilai chi square kurang dari 11.

Analisis utama berupa regresi ganda. Analisis diawali uji model melalui koefisien determinasi dan uji-F. Model penelitian diterima dan bisa untuk analisis lanjutan jika nilai koefisien determinasi lebih dari $50 \%$ dan probabilitas F kurang dari 0,05.

Analisis diakhiri dengan uji hipotesis. Analisis dengan menggunakan koefisien regresi dalam model persamaan berikut:

$\mathrm{Y}=\mathrm{a}+\mathrm{b} 1 \mathrm{X} 1+\mathrm{b} 2 \mathrm{X} 2$

dimana $\mathrm{Y}$ adalah loyalitas pelanggan, $\mathrm{X} 1$ adalah kualitas layanan dan $\mathrm{X} 2$ mewakili kepercayaan pelanggan.

Pengujian hipotesis dilakukan terhadap hasil analisis yaitu koefisien regresi pada persamaan regresi linier ganda dan uji-t. Hipotesis diterima jika probabilitas t hasil penelitian kurang dari 0,05. 


\section{Hasil Penelitian}

Responden berjumlah 40 yaitu 26 orang laki-laki sedangkan sisanya perempuan 14 orang. Sebagian besar berpendidikan SMA sederajat yaitu 19, berikutnya 15 orang tamatan Diploma dan 6 orang tamatan S1.

Tabel 1. Validitas Reliabilitas Kualitas layanan

\begin{tabular}{|c|c|c|c|c|}
\hline Variabel/Indikator & Mean & $\mathrm{r}$ & $\begin{array}{c}\text { Cronbach's } \\
\text { Alpha }\end{array}$ & Hasil \\
\hline Kualitas Layanan & & & 0,960 & Reliabel \\
\hline - Produk yang tepat & 5.000 & .745 & & Valid \\
\hline - Kesesuaian pesanan & 4.800 & .733 & & Valid \\
\hline - Kecepatan layanan & 4.900 & .964 & & Valid \\
\hline - Kelengkapan informasi & 4.900 & .964 & & Valid \\
\hline - Kesesuaian promosi & 4.900 & .964 & & Valid \\
\hline - Penanganan keluhan & 4.900 & .964 & & Valid \\
\hline - Kecepatan respon & 4.800 & .733 & & Valid \\
\hline
\end{tabular}

Sumber: Data Penelitian diolah (2020)

Nilai korelasi tiap indikator kualitas layanan pada tabel 1 antara 0,733 sampai dengan 0,964 . Nilai tersebut lebih besar dari 0,3 tanda seluruh indikator valid. Nilai cronbach's alpha dari perhitungan telah lebih besar dari kriteria $(0,960>$ $0,600)$ maka reliabilitas kualitas layanan terpenuhi.

Tabel 2. Validitas Reliabilitas Kepercayaan

\begin{tabular}{|c|c|c|c|c|}
\hline Variabel/Indikator & Mean & $\mathrm{r}$ & $\begin{array}{c}\text { Cronbach's } \\
\text { Alpha }\end{array}$ & Hasil \\
\hline Kepercayaan & & & 0,977 & Reliabel \\
\hline - Percaya entitas & 4.500 & .972 & & Valid \\
\hline - Percaya produk & 4.600 & .974 & & Valid \\
\hline - Percaya promosi & 4.600 & .974 & & Valid \\
\hline - Percaya harga & 4.500 & .972 & & Valid \\
\hline - Percaya lokasi & 4.500 & .972 & & Valid \\
\hline - Percaya layanan & 4.600 & .974 & & Valid \\
\hline - Percaya respon & 4.500 & .972 & & Valid \\
\hline
\end{tabular}

Sumber: Data Penelitian diolah (2020)

Nilai korelasi tiap indikator kepercayaan pada tabel 2 antara 0,972 sampai dengan 0,974 . Korelasi tersebut lebih besar dari 0,3 tanda seluruh indikator valid. Cronbach's alpha telah melebihi kriteria $(0,977>0,600)$ maka reliabilitas kepercayaan terpenuhi.

Nilai korelasi tiap indikator loyalitas pada tabel 3 antara 0,873 sampai dengan 0,885 . Nilai tersebut lebih besar dari 0,3 tanda seluruh indikator valid. Nilai 
cronbach's alpha telah lebih besar dari kriteria $(0,963>0,600)$ maka reliabilitas loyalitas terpenuhi.

Tabel 3. Validitas Reliabilitas Variabel Loyalitas

\begin{tabular}{ccccc}
\hline Variabel/Indikator & Mean & r & $\begin{array}{c}\text { Cronbach's } \\
\text { Alpha }\end{array}$ & Hasil \\
\hline Loyalitas & & & 0,963 & Reliabel \\
- Keinginan membeli & 5.100 & 885 & & Valid \\
- Pembelian berulang & 5.200 & .873 & & Valid \\
- Testimoni positif & 5.200 & .873 & & Valid \\
- Mengajak kenalan & 5.100 & .885 & & Valid \\
- Rekomendasi produk & 5.100 & .885 & & Valid \\
- Tidak beralih produk & 5.200 & .873 & & Valid \\
- Tidak beralih penjual & 5.100 & .885 & & Valid \\
\hline
\end{tabular}

Sumber: Data Penelitian diolah (2020)

Hasil uji normalitas pada variabel kualitas layanan mendapatkan chi-square hitung sebesar 9,800. Variabel Kepercayaan diperoleh nilai chi-square hitung sebesar 5,300, dan Loyalitas pelanggan mendapatkan chi-square sebesar 9,000 kriteria chi-square sebesar 11,000. Karena chi-square kurang atau lebih kecil dari kriteria yang ditetapkan maka masing-masing variabel berdistribusi normal.

Tabel 4 menunjukkan besarnya nilai $\mathrm{R}$ atau korelasi antara kualitas layanan dan kepercayaan dengan loyalitas sebesar 0,918. Koefisien Determinan atau R Square sebesar 0,842 menunjukkan 84,2\% variasi loyalitas terjadi karena kualitas layanan beriringan dengan kepercayaan.

Tabel 4. Koefisien Determinan

\begin{tabular}{ccccc}
\hline Model & R & R Square & $\begin{array}{c}\text { Adjusted } \\
\text { R Square }\end{array}$ & $\begin{array}{c}\text { Std. Error of } \\
\text { the Estimate }\end{array}$ \\
\hline $\mathbf{1}$ & $.918^{\mathrm{a}}$ & .842 & .834 & .48867
\end{tabular}

Predictor: (Constant), Kepercayaan (X2), Kualitas (X1)

Dependent Variable: Loyalitas (Y)

Sumber: Data diolah (2020)

Tabel 5. Hasil Uji F

\begin{tabular}{lccccc}
\hline \multicolumn{1}{c}{ Model } & $\begin{array}{c}\text { Sum of } \\
\text { Squares }\end{array}$ & Df & $\begin{array}{c}\text { Mean } \\
\text { Square }\end{array}$ & F & Sig. \\
\hline Regression & 47.139 & 2 & 23.570 & 98.700 & $.000 \mathrm{a}$ \\
Residual & 8.836 & 37 & .239 & & \\
Total & 55.975 & 39 & & & \\
\hline
\end{tabular}

Predictors: (Constant), Kepercayaan (X2), Kualitas layanan (X1)

Dependent Variable: Loyalitas (Y)

Sumber: output spss, 2020 
Hasil uji F pada tabel 5 di peroleh nilai sebesar 98,700. Tingkat signifikansi atau probabilitas F sebesar Sig. F = 0,000. Karena karena Sig. F lebih kecil atau kurang dari 0,05, model persamaan regresi linier ganda hasil analisis layak untuk menjelaskan pengaruh variabel dalammodel.

Tabel 6. Uji Hipotesis

\begin{tabular}{llccccc}
\hline & & B & Std.Error & Beta & $\mathrm{t}$ & Sig. \\
\hline \multirow{2}{*}{1} & (Constant) & 1.430 & .308 & & 4.637 & .000 \\
& Kualitas layanan (X1) & .585 & .099 & .660 & 5.888 & .000 \\
& Kepercayaan (X2) & .215 & .081 & .297 & 2.655 & .012 \\
\hline
\end{tabular}

a. Dependent Variable: Loyalitas (Y)

Sumber: Output SPSS, 2020

Model regresi linier berganda sesuai hasil analisis pada tabel 6 adalah:

$Y=1,430+0,585 X 1+0,215 X 2$

Kualitas layanan dalam penelitian ini mempengaruhi loyalitas, dimana analisis menemukan nilai koefisien regresi positif sebesar $b 1=0,585$ dengan nilai Sig. $=$ 0,000. Probabilitas dibawah 0,05 berarti signifikan, dengan demikian kualitas layanan yang baik mendorong tumbuhnya loyalitas.

Kepercayaan dalam penelitian ini mempengaruhi loyalitas, dimana analisis menemukan nilai koefisien regresi positif sebesar b2 $=0,215$ dengan nilai Sig. $=0,012$. Probabilitas dibawah 0,05 berarti signifikan, dengan demikian kepercayaan mendorong tumbuhnya loyalitas.

\section{Pembahasan}

Penelitian menghasilkan temuan berupa valid dan reliabelnya kuesioner sebagai pengumpul data. Penelitian menghasilkan model yang baik dan layak untuk diinterpretasikan.

\subsection{Pengaruh kualitas layanan terhadap loyalitas.}

Kualitas layanan berpengaruh searah atau positif $(\mathrm{b} 1=0,585)$ terhadap loyalitas pelanggan dengan hasil uji signifikan. Kualitas pelayanan yang makin baik akan meningkatkan loyalitas pelanggan. Hal tersebut menunjukkan indikator kualitas pelayanan yang terdiri dari Kualitas produk, Kesesuaian pesanan, Kecepatan layanan, Kelengkapan informasi, Kesesuaian promosi, Penanganan keluhan dan Kecepatan respon perlu diperhatikan, karena berkonsekuensi terhadap loyalitas pelanggan.

Penelitian ini sejalan dengan penelitian sebelumnya (Trisusanti, 2017). Penelitian lain juga mendapatkan temuan yang sama (Zakiy, 2017) pada Bank Syariah dan 
(Alwi, 2018) pada pembelian online. Penelitian menguatkan perlunya respon cepat atas keluhan pelanggan dan jaminan kesesuaian pelanggan sebagai bagian penting dalam layanan.

\subsection{Pengaruh kepercayaan terhadap loyalitas}

Kepercayaan berpengaruh positif $(b 2=0,215)$ terhadap loyalitas pelanggandan signifikan. Kepercayaan yang makin tinggi meningkatkan loyalitas pelanggan. Hal tersebut menunjukkan bahwa peningkatan nilai dari beberapa indikator variabel kepercayaan dalam penelitian ini berupa kepercayaan terkait dengan entitas, produk, promosi, harga, lokasi, layanan dan respon berkonsekuensi pada peningkatan loyalitas pelanggan.

Penelitian sebelumnya ditemukan adanya pengaruh positif antara kepercayaan terhadap pembelian ulang (Dwipayana \& Sulistyawati, 2018; Soegoto, 2013). Penelitian lainnya menemukan adanya pengaruh kepercayaan mitra terhadap loyalitas pelanggan (Taufik, 2017), demikian pula penelitian lainnya (Tumbel, 2016, ; Lapasiang, Moniharapon \& Loindong, 2017; Alwi, 2018; Trisnawati, Sume \& Muniroh, 2020). Penelitian juga mendukung temuan pada bidang properti (Nurbani, Mulyanto, Wardani, Andriyani, 2019), handphone oppo (Huda dan Nugroho, 2020). Penelitian menguatkan perlunya keyakinan konsumen pada informasi di seluruh elemen bauran pemasaran.

\section{Kesimpulan}

Kualitas layanan berpegaruh terhadap loyalitas. Kepercayaan berpengaruh terhadap loyalitas. Keduanya memiliki arah positif.

Bagi usaha UMKM khususnya usaha kuliner sangat perlu memperhatikan kualitas layanan yang diberikan pada konsumen, demikian pula dengan pentingnya menanamkan sekaligus meningkatkan kepercayaan pelanggan agar dapat meraih dan mempertahankan loyalitas pelanggan.

\section{Daftar Pustaka}

Alwi, T. (2018), Pengaruh Kualitas Pelayanan Online dan Kepercayaan Online terhadap Loyalitas Pelanggan Online, Prosiding Manajerial dan Kewirausahaan, Vol. 3 No. 1, 69 - 84, Penerbit LP2M STIE IPWI Jakarta.

Andriyani, M., \& Ardianto, R. (2020). Pengaruh Kualitas Layanan dan Kualitas Produk Terhadap Kepuasan Nasabah Bank. EKOMABIS: Jurnal Ekonomi

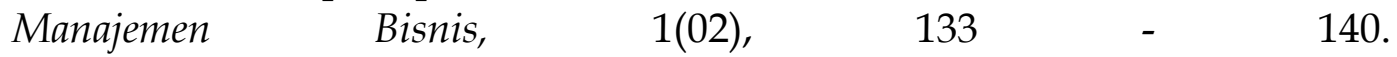
https://doi.org/10.37366/ekomabis.v1i02.73

Asti, E., \& Ayuningtyas, E. (2020). Pengaruh Kualitas Pelayanan, Kualitas Produk dan Harga Terhadap Kepuasan Konsumen. EKOMABIS: Jurnal Ekonomi Manajemen Bisnis, 1(01), 1 - 14. https://doi.org/10.37366/ekomabis.v1i01.2 
Dwipayana, B., Sulistyawati, E. (2018), Peran Kepuasan Dalam Memediasi Pengaruh Kepercayaan Terhadap Niat Beli Ulang Pada Go-Food di FEB UNUD, E-Jurnal Manajemen Unud, Vol. 7, No. 10, 5197-5229 ISSN: 2302-8912

Hurriyati, R. (2005). Bauran Pemasaran Dan Loyalitas Konsumen, Penerbit Cv. Alfabeta, Bandung.

Lapasiang, D., Moniharapon, S., Loindong, S., (2017), Pengaruh Kepercayaan Dan Komitmen Terhadap Loyalitas Nasabah Pada PT. Pegadaian (Persero) Cabang Karombasan Manado, Jurnal EMBA, Vol.5 No.3, Hal.3068-3077

Mulyanto, H. dan Wulandari, A., (2010), Penelitian Metode dan Anlisis. Semarang : cv Agung

Mulyanto, H., Rasipan, Andriyani, M. (2018). Reputasi dalam Mendorong Kepercayaan dan Minat Beli Konsumen Produk Makanan UMKM di Cileungsi, Jurnal Manajemen Kewirausahaan. Vol 15 No. 2. e-ISSN 2654-9247. p_ISSN 18581048, DOI: http:/ / dx.doi.org/10.33370/jmk.v15i2.270

Nawawi, H. (2003), Metode Penelitian Bidang Sosial, Penerbit Gajah Mada Universitas Press, Yogyakarta.

Nurbani, A., Mulyanto, H., Wardani, M.K., Andriyani, M. (2019). Pengaruh Bauran Pemasaran terhadap Kepuasan dan Kepercayaan serta Dampaknya terhadap Loyalitas Konsumen. Jurnal Manajemen Kewirausahaan, 16(2). 109120. DOI: http://dx.doi.org/10.33370/jmk.v16i2.346 .

Huda, O.K., Nugroho, A.T. (2020). Pengaruh Word of Mouth dan Citra Merek Terhadap Loyalitas Pelanggan Smartphone Oppo Dimediasi Kepercayaan Merek, Jurnal Pengembangan Wiraswasta, Vol. 17 No. 1, 141-150, DOI: http://dx.doi.org/10.33370/jpw.v22i02.436

Soegoto, A. S. (2013), Persepsi Nilai dan Kepercayaan terhadap Kepuasan dan Dampaknya terhadap Loyalitas Konsumen, Jurnal EMBA Vol.1 No.3 September 2013, Hal. 1271-1283

Sugiyono (2003), Metode Penelitian Bisnis, Badan Penerbit ALFABETA Bandung. Taufik (2017), Pengaruh Kepercayaan Mitra dan Komitmen Perusahaan terhadap Loyalitas Mitra Pengemudi Ojek Online, Jurnal Manajemen Kewirausahaan, Vol. 14, No. 2, hal. 223-232, LP2M STIE IPWI Jakarta

Trisnawati, M.N., Sume, S.A., Muniroh, L. (2020), Pengaruh Kepercayaan Merek Dan Kualitas Produk Terhadap Loyalitas Pelanggan, Jurnal Ilmu Manajemen, Vol. 3, No. 2, Mei 2020, Hal 171-176

Trisusanti, Y. (2017), Pengaruh Kualitas Pelayanan Dan Kepercayaan Terhadap Loyalitas Nasabah (Studi pada Bank BNI Syariah Kantor Cabang Pekanbaru), JOM FISIP Vol. 4 No. 2, hal 1-16.

Tumbel, A. (2016), Pengaruh Kepercayaan Dan Kepuasan Terhadap Loyalitas Nasabah Pada PT Bank BTPN Mitra Usaha Rakyat Cabang Amurang 
Kabupaten Minahasa Selatan, Jurnal LPPM Bidang EkoSosBudKum, Volume 3 Nomor 1, hal 64-79.

Zakiy, M. (2017), Pengaruh Kualitas Layanan Terhadap Loyalitas Nasabah Bank Syariah Dengan Kepuasan Nasabah Sebagai Variabel Intervening, Jurnal Ekonomi dan Bisnis Islam, Vol. 3, No. 1, hal 26-38 